minims diluted with water, with which it makes a milkylooking mixture. The tincture has a strong and character. istic odour and taste, and is of a bright maize colour. It may be given with iron, if a greenish colouration be permissible. Birmingham.

\section{A SINGULAR CASE OF AURAL GROWTH.}

By GuRdon Holmes, M.D.,

PHYSICIAN TO THE MUNICIPAL THROAT AND FAR INFIRMART, LONDON CONSULTING PHYSICIAN TO THE SHEFFIELD EAR AND THROAT HOSPITAL.

The following case is probably unique in the published annals of ear disease, and therefore deserves to be placed on record.

In the latter end of 1889 T. A. H-, a healthy-looking and well-grown boy of fifteen, was brought to me on account of deafness of one ear, which had only just been discovered. On examining the right meatus I found the entrance veiled by a film of purulent discharge. When this was cleared away a growth came into view, having the appearance of an ordinary polypus and filling up the meatus to within a couple of lines of its external outlet. To the probe this growth evinced an unusual firmness, and I concluded that I had to deal with a polypus of remarkable toughness. I applied Wilde's snare, however, in the ordinary way, but brought awily only about a quarter of an inch of the growth. Again I essayed, but the second time removed only a thin slice, less than a line in thickness. Exploration with a probe now revealed the fact that the eneatus was blocked at about a third of its length from the atside by a solid body, presenting all the characteristics of \&n exostosis, from the external face of which the soft growth had arisen. Under suitable treatment with astringents \&c. the raw surface healed up, and as soon as the parts were clear of all discharge it was found that hearing was as verfect, or nearly, as with the sound ear. Nevertheless by ocular inspection it was scarcely possible to detect a crevice through which the sound waves could reach the tympanum. No doubt there is a cavity behind the projecting bone, and on the principle of hydraulics, a very small aperture is sufficient to influence fully from outside the body of air contiguous to the tympanic membrane. Whether the stenotic condition of the meatus is due to some congenital deformity or to an ordinary exostosis it seems not easy to determine but I incline to believe that there is a morbid growth from the bone. I have recently heard of the case, more than a year having elapsed, and it appears that the boy has suffered to inconvenience since the local treatment was finished, so that up to date the ear remains practically as useful as if unaffected. An operation is therefore deferred sine die, unless further symptnms arise which may demand it.

Cases of exostosis of the auditory meatus are extremely rare--from my own experience,--not more than one in 3000 ordinary instances of ear disease. In two previous cases I have seen there was a purulent discharge, apparently from behind the growth. In such instances I have read that a soft polypus has been discovered posterior to the exostosis after its removal. Ordinary polypus of the ear is decidedly frequent-fully 2 or 3 per cent. of all ear cases. They occur at all ages up to about forty, and I have seen at least one in an infant of a few months old. I do not remember seeing a case after forty, nor do I think they often have their origin much beyond the period of adolescence.

Finsbury-square, E.C.

\section{A CASE OF MONSTROSITY.}

By W. Armstrong, L.R.C.P., L.R.C.S. \&e.

ON Feb. 7th I was called to attend on Mrs. C- at 2 P.M. in her second confinement. She did not expect the birth till the end of March. About 11 A.M. the membranes had ruptured, and a large amount of fluid escaped; from that time until my arrival there had been regular though slight hæmorrhage. On examination the rectum was found to be loaded with fieces, the os being about the size of a threepenny piece. An enema of soap and warm water was edministered, and the bowels were freely opened. As there were no pains for an hour and a half I left, promising to call later on. I returned at $7 \mathrm{I} . \mathrm{M}$. The patient had had strong pains since four o'clock. On vaginal examination $I$ felt in the vagina a rounded mass, which I took to be a shoulder, and on pushing the finger onwards I felt four or five sharp bony prominences, above which was a soft mass. I then pulled on the arm, and brought down a very small hand. I then introduced three fingers, and hooked on to the fœtus and pulled it down. The placenta was dislodged in a similar way. In this case there was no history of shock or fright during pregnancy. The previous (first) confinement was characterised by complete inertia, and the child was stillborn. Patient is always very anzemic. The fotus presented the following appearance:-Sex, male. Length between seven and eight inches. The head was continuous with the body, back, and front, the neck being absent. The limbs were long, and feet and hands relatively large; the abdomen much swollen. With these exceptions the body was normal in appearance. The face resembled that of a frog, the eyes very protuberant, and the tongue protruding

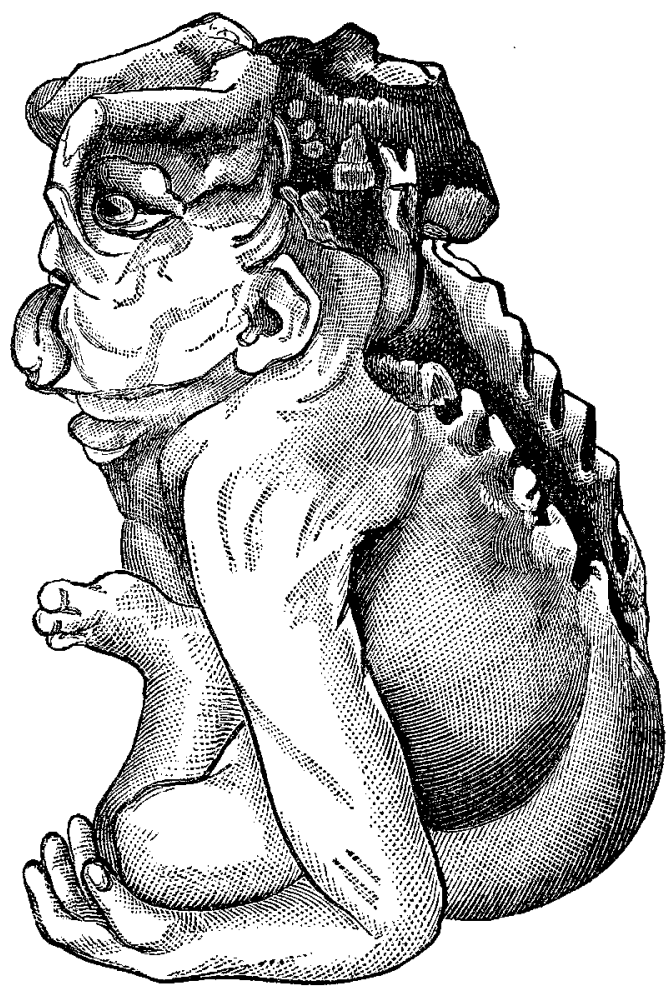

from the mouth. Immediately above the eyes the head presented a flattened surface at right angles with the face. The skin of the face was continued over this surface to about the level of the ears, from which line backwards extended a thin red membrane, which had evidently contained fluid, and formed a sac, and this membrane continued backwards down the spine, forming the roof of the open vertebral canal. Just behind a line dra wn between the two ears were two bony prominences on each side, projecting vertically considerably above the flat upper surface of the head. Immediately behind the remains of the sac, in the occipital region, was a deep depression, and thence down the spine extended a broad open groove, bounded on either side by six bony prominences, and terminating just above the sacrum. The sketch conveys a very good idea of the appearance of the monster.

Pontesbury, Salop.

\section{CASE OF PUERPERAL FEVER COMMENCING NINE DAYS AFTER DELIVERY.}

By Geo. H. SAlter, L.R.C.P.Ed., M.R.C S.ENG.

I THINK a few notes on this case may be of sufficient in. terest to find a place in the columns of THE LANCET.

On Aug. 30th at 7.30 A.M. Mrs. D- gave birth to a male child, this being her fifth confinement. She was attended by a midwife. On Sept. 8 th at 11 A.M. by request I first saw Mrs. D —. The woman in attendance told me "the labour had been easy, the afterbirth coming away half an hour after the child, and that until 9 o'clock that morning the mother had been doing splendidly. At that time she begau to shiver, looked strange about the eyes, and talked queerly. She had had plenty of milk, had suckled the infant several times through the previous night, 
and there had been no bad smell about the discharge." On examination I found the patient looking terribly ill, dorsal decubitus, knees not being drawn up; she was more or less delirious. Skin moist, tongue thickly furred. Temperature $104^{\circ}$; pulse 140 ; respiration 40 per minute. $\Lambda$ bdomen was not swollen, and there was not the least tenderness on pressure above the pubes. The lochia were not offensive, but the condition of the bedclothes was not so clean as one could wish. This I saw remedied, ordered her the usual diet (milk and meat broth), and ordered a mixture containing ten grains of salicylate of soda with two minims of tincture of aconite every two hours, promising to call again in the evening. At 7.30 P.M. I found her in much the same condi. tion. She had been delirious through the day, but had taken freely of nourishment without vomiting. Had passed two copious and offensive motions. Temperature $105^{\circ}$; pulse 160 ; tongue dry. I syringed her with diluted Condy and ordered an ounce of brandy every four hours. On the 9 th I visited her twice. The temperature at 11 A.M. was $105^{\circ}$; at 8 P.M. $104^{\circ}$. Her general condition was much the same. The breasts were soft and contained very little milk. The lochia had ceased. There was no swelling of the abdomen or tenderness. She had taken nourishment freely, and the bowels had not been moved. She had not vomited. Had dozed at times, and been less delirious during the later part of the day. She was syringed morning and evening. On the 10th, at 11 A.M., she expressed herself as feeling much better, and certainly looked so. She had taken plenty of nourishment without vomiting, and had slept fairly well during the night. Temperature $102^{\circ}$; pulse 108. I syringed her as before, and gave a mixture containing five grains of quinine every three hours, and promised to call the following morning. On the 11th I was sent for at $8 \mathrm{~A}, \mathrm{M}$, and found her condition as follows: Face anxious; slightly jaundiced tint; lips bluish; skin moist; dry tongue, with sordes about the teeth. She was quite conscious, and complained of cough and of pain about the wrists, elbows, and knees, which were slightly swollen. The abdomen was much swollen. There had been some diarrhoa, but no vomiting, through the night. The nourishment had been taken freely. Temperature $102^{\circ}$; pulse 130 ; respiration 40 per minute. The sputa were brownish, and on percussion and auscultation there were well-marked signs of pneumonia in both lungs. From this time onward she went from bad to worse, and died on Sept. 14th at 11.30 A.M.

I have seen many cases of puerperal fever during the time $I$ have been practising, and in all previous to this my experience has accorded with what is stated in the works I possess on Midwifery. That the initial rigor in this case did not take place until the ninth day I cannot doubt, as the patient told me she had never felt better than she did until the morning of Sept. 8th. Information gained from those who had seen her on the 6 th and 7 th tended to corroborate this. No doubt the exciting cause of the disease was lack of cleanliness; and I imagine, as the woman was very stout and flabby, the reparative process was more slowly accomplished, and thereby the susceptibility to septic influences unduly prolonged. So good an authority as Lusk ${ }^{1}$ writes:- "The third day is the one upon which urdinarily the beginning of the fever is to be anticipated. After the fifth day an attack is rare, and at the end of a week patients may be regarded as having reached the point of safety." Other authors I have at hand take much the same view, and although they agree in saying that the disease may occur later, I fancy a case in which it commenced on the ninth day is sufficiently rare to make it worthy of record.

Learmonth, Victoria, Australia.

1 The Science and Art of Midwifery, by Wm. Thompson Lusk, M.A., M.B.; 1st edition, p. 620 .

The Royal Surrey County Hosprtal.-The annual report for 1890 is satisfactory. The continued generous support received has relieved the committee from present financial anxiety. The receipts on current account$£ 4204 \quad 17 s$. - have been adequate to discharge the disbursements and leave a balance of $£ 848 s, 1 d$ in hand. The honse surgeon's report showed that the in-patients numbered 774 . The home patients on the books were 409 and visits made 1395. The total of out-patients was 4640 and attendances 11,006. The proposal to abolish the attendance of the house surgeon on home patients residing within a mile of the Town Hall, Guildford, has been referred to a committee to consider and report to a special meeting of the governors.

\section{A 嗮lirtor}

\section{HOSPITAL PRACTICE, BRITISH AND FOREIGN.}

Nulla autem est alia pro certo noscendi via, nisi quamplurimas et mos borum et dissectionum historias, tum aliorum tum proprias collectas habere, et inter se comparare.-MorgagNI De. Sed. et Caub. Morb. lib. iv. Procemium.

\section{EASTERN FEVER HOSPITAL, HOMERTON.}

A CASE OF PURPURA FULMINANS; NECROPSY; REMARKS

(Under the care of Dr. CoLLIE.)

PURPURA of the severity exhibited in the case of this patient is fortunately of very rare occurrence in this country, and the resemblance which it bears to the cases described by Dr. Henoch is pointed ont by Dr. Collie in his remarks. A more recent contribution to the literature of the disease will be found in the Archives of Pediatrics for December of last year by Dr. Jackson, of Boston, U.S.A. His communication was founded on the observations of the case of a boy aged five, who had died under his care on the fifth day of the disease. The patient had suffered from severe hæmorrhages from the mucous membranes (epistaxis, hæmatemesis, melæna, and hæmaturia), as well as from large subcutaneous extravasations of blood. The following ancount is from notes by Miss Fleury, assistant medical officer.

F. B. D was admitted into the hospital about 9 P.M. on Nov. 11th last. About Oct. 20th he had an attack of scarlet fever, which he appeared to be passing safely through when the "eruption" which is about to be described was observed on Nov, 10th, about three weeks from the com mencement of the scarlet fever. On admission the patient was a pale, thin boy, nine years of age. His expression was placid, and his intelligence remarkably acute. Over the extensor aspect of the left elbow a large ecchymosis extended some way down the forearm. There was an extensive ecchymosis over the right hip, and one on the calf of each leg. The ecchymoses appeared to be recent, anc at their margins the extravasated blood was of a bright. red colour. There was extreme tenderness of the skin, but otherwise the patient made no complaint of pain. The tongue was fairly clean, and the gums sound. There was no hæmorrhage into the conjunctiva, and there was none from the mucous membranes. The pulse was fairly good, and the temperature $98.6^{\circ} \mathrm{F}$. There was a little branny desquamation on the face. Mind clear. He passed a restless night, but took his nourishment readily, apparently being very thirsty. He complained of "pins and needles" sensation all over, but at 7 A.M. he was reported to have been bright and cheerful. He passed two ounces of urine free of blood during the night, and there was no motion from the bowels. About $8 \mathrm{~A}$.M. violent vomiting came on. He cried much when moved in bed, and complained of pain in the abdomen. At 11 A.Mr. a new ecchymosis wag. observed behind the left ear. His face was now very pale, pinched, and drawn, and generally he appeared to be in great distress. It was clear that he was sinking, but his mind continued clear. He died about noon; that is, about sixteen hours after admission, and about forty-eight after the appearance of the "eruption."

Necropsy, forty-eight hours after death.-Rigor mortis was very marked. There was a large ecchymosis on the back extending downwards from the right shoulder; also one over the left hip. The patches were somewhat sym. nuetrical. There was some fluid in each pleural cavity, but more in the right than in the left. Lungs were anxmic, but otherwise normal. The heart contained no clots, but the walls were somewhat thin and flabby. The liver and kidneys were anæmic. Spleen not enlarged. Intestines were very anæmic, containing a little feculent matter, walls very thin. There were a few drops of urine in the bladder, no fluid in the peritoneal cavity. Patchy congestion of the tonsils. On examination of the brain, the arachnoid was found to be milky, the convolutions somewhat flattened, and a small quantity of serum in the ventricles. There was no extravasation of blood in any of the internal organs.

Remarks by Dr. CoLLIE.-The interest of this case is: 